ANÁLISE REGIONAL DAS MESORREGIOES DO ESTADO DO PARANÁ NO FINAL DO SÉCULO XX

JANDIR FERRERA DE LIMA, LUCIR REINALDO ALVES, MOACIR Piffer e Carlos Alberto Piacenti

CUSTO NA DÍVIDA PÚBLICA INTERNA DA REDUÇĀO DA VULNERABILIDADE EXTERNA BRASILEIRA ATRAVESS DO AUMENTO DAS RESERVAS INTERNACIONAIS

ROBERTO MEURER

DETERMINAČÃO DE UM MODELO DE PREVISÃO UNIVARIADO PARA PREÇOS DE LEITE PAGOS AOS PRODUTORES EM SANTA CATARINA

ARLei LUiz Fachinello e Mirian Rumenos Piedade Bacch!

VIABILIDADE DE ESTRATÉGIAS DE HEDCE COM CONTRATOS FUTUROS DE BOI GORDO NO BRASIL DIANA de MEDEIROS BAPTISTA E DANILO ROLIM DIAS DE AGUIAR

ATAQUES ESPECULATIVOS E CRISES CAMBIAIS NA ARGENTINA E NO BRASIL: UMA ANÁLISE COMPARATIVA KELLEN FrAGa DA SIIVA E FERnANDO FERRARI FILHO

A TEORIA DOS FUNDOS DE EMPRÉSTIMOS: UM ESTUDO DOS MODELOS AGREGADOS NEOCLÁSSICO E KEYNESIANO

ALAIN HERSCOVICI

CRIME ECONÔMICO NO PARANÁ: UM ESTUDO DE CASO SALETE POLONIA BoriLLI E PERY Francisco AsSIS SHIKIDA

APLICAÇĀO DA NOVA ECONOMIA INSTITUCIONAL AO AMBIENTE PORTUÁRIO: ANÁLISE DOS CUSTOS DE TRANSAÇĀO NO PORTO DE SANTOS

CinTIA RETZ LUCCI, ALCINDO FERNANDES GONÇALVES E

ROBERTO FAVA SCARE

REDUÇÃO DE MANDATOS LEGISLATIVOS: O DEBATE ADORMECIDO

Francisco josé de Queiroz PINHeiro, Charles lima de ALMEIDA E TITO BELCHIOR SILVA MOREIRA

ANÁLISE ECONÔMICA E AMBIENTAL DE SISTEMAS DE TERMINACCÃO DE SUINNOS COM A APLICACCÃO DOS CONUUNTOS FUZZY

JULIO EDUARDo ROHENKOHL, ORLANDO MARTINELLI E MARCOS ALVES DOS REYS

RESENHA: THE GLOBAL EVOLUTION OF INDUSTRIAL RELATIONS EVENTS, IDEAS AND THE IIRA

CARLOS HENRIQUE HoRN
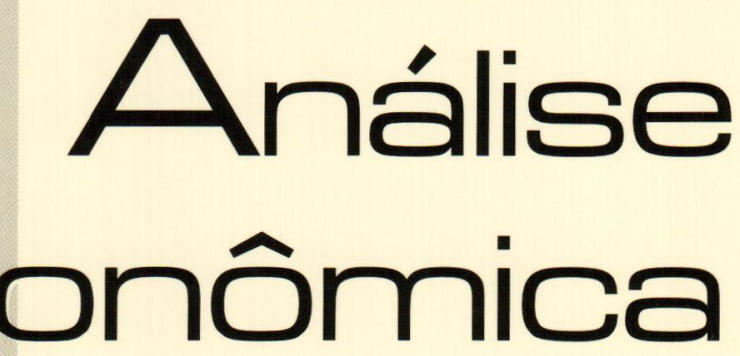


\section{A Revista Análise Econômica agradece a colaboração dos pareceristas dos números 45 e 46 , abaixo relacionados}

Abraham Benzaquen Sicsu

Adelar Fochezalto

Ademar Ribeiro Romeiro

Ademir Clemente

Alexandre Stamford da Silva

Ana Lucia Kassouf

Andre Luis Rossi de Oliveira

Andre Tosi Furtado

Andrea Sales Soares de Azevedo Melo

Angela Antonia Kageyama

Antonio Wilson Ferreira Menezes

Armando João Dalla Costa

Bernardo Mueller

Carlos Frederico Leao Rocha

Claudio Roberto Fóffano Vasconcelos

Cláudio Diissey Shikida

Clesio Lourenco Xavier

Dullio de Avila Berni

Eliezer Martins Diniz

Emerson Fernandes Marçal

Eugenio Lagemann

Fernando Ferrari Fitho

Francisco Casimiro Filho

Franklin Leon Peres Serrano

Frederico Gonzaga Jayme Jr.

Geraldo Edmundo Silva Jr.

Helder Ferreira de Mendonça
Helder Queiroz Pinto Junior Izabel Cristina Takitane

Joaquim José Martins Guilhoto

Joilson Dias

Jose Gabriel Porcile Meirelles

José Rubens Damas Garlipp

Julio César de Oliveira

Lovois de Andrade Miguel

Marcelo Savino Portugal

Marcio Holland de Brito

Marco Aurelio Crocco Afonso

Marcos Costa Holanda

Mônica Viegas Andrade

Paulo Dabdab Waquil

Paulo Sergio Fracalanza

Pedro Bandeira

Pedro Valentim Marques

Pery Francisco Assis Shikida

Renato Leite Marcondes

Roberto Camps Moraes

Ronald Otto Hilbrech

Ronaldo de Albuquerque e Arraes

Ronaldo Seroa da Motta

Thompson Almeida Andrade

Tito Belchior Silva Moreira

Valmor Marchetti

Vladimir Kuhl Teles 


\title{
Análise regional das mesorregiões do estado do Paraná no final do século XX
}

\author{
Jandir Ferrera de Lima* \\ Lucir Reinaldo Alves** \\ Moacir Piffer*** \\ Carlos Alberto Piacenti****
}

Resumo: O objetivo deste artigo é o de analisar o desempenho setorial das mesorregiōes do Paraná, no período de 1991 a 2000. Foi utilizado o método de análise regional. Os resultados apontaram uma concentração das atividades secundárias e terciárias nas mesorregiões com maior densidade populacional do Estado, quais sejam: Oeste, Norte Central e Metropolitana de Curitiba. Outrossim, verificou-se que a dinâmica do Estado está pautada nas atividades secundárias e terciárias, com destaque para o comércio e setor público.

Palavras-chave: Análise Regional, Desenvolvimento Regional, Mesorregiões, Paraná.

Abstract: The objective of this article is to analyze the sectorial performance of the mesoregions of the Paraná state, in the period from 1991 to 2000. The method of regional analysis was used. The results had pointed a concentration

* Ph.D. em Desenvolvimento Regional pela Université du Québec à Chicoutimi (UQAC) - Canadá. Professor Adjunto do Colegiado de Economia na Universidade Estadual do Oeste do Paraná (UNIOESTE)/Campus de Toledo. Pesquisador do Grupo de Estudos e Pesquisas em Agronegócio e Desenvolvimento Regional (GEPEC). Pesquisador Associado do GRIR-UQAC Endereço: Rua da Faculdade, 645, Jd. La Salle, CEP: 85903-000, Toledoz-PR, Fone: (45) 3379 7000. E-mail: jandirbr@yahoo.ca, jandir@unioeste.br

** Economista pela Universidade Estadual do Oeste do Paraná (UNIOESTE)/Campus de Toledo. Mestrando em Desenvolvimento Regional pela Universidade de Santa Cruz do Sul (UNISC). Bolsista pela Capes. Membro do Grupo de Estudos e Pesquisas em Agronegócio e Desenvolvimento Regional (GEPEC) e do Grupo Dinâmicas Sócio-Econômicas Nacionais e Regionais Comparadas (DISENREC). Endereço: Rua Augusto Spengler, 399, Apto 303, Jd Universitário, CEP: 96815-020, Santa Cruz do Sul-RS, Fone: (51) 8175 3553.E-mail: lucir_a@hotmail.com

***Doutorando em Desenvolvimento Regional pela Universidade de Santa Cruz do Sul (UNISC). Professor Assistente do Colegiado de Economia na Universidade Estadual do Oeste do Paraná (UNIOESTE)/Campus de Toledo. Pesquisador do Grupo de Estudos e Pesquisas em Agronegócio e Desenvolvimento Regional (GEPEC) e do Grupo Dinâmicas Sócio-Econômicas Nacionais e Regionais Comparadas (DISENREC). Endereço: Rua da Faculdade, 645, Jd. La Salle, CEP: 85903-000, Toledo-PR, Fone: (45) 3379 7000.E-mail: piffer@unioeste.br

* * * Doutorando em Economia Aplicada pela Universidade Federal de Viçosa (UFV). Professor Assistente do Colegiado de Eoonomia da Universidade Estadual do Oeste do Paraná (UNIOESTE)/Campus de Toledo. Pesquisador do Grupo de Estudos e Pesquisas em Agronegócio e Desenvolvimento Regional (GEPEC). Endereço: Rua da Faculdade, 645, Jd. La Salle, CEP: 85903-000, Toledo-PR, Fone: (45) 3379 7000. E-mail: piacent8@@yahoo.com.br

-Recebido em junho de 2005. Aceito em outubro de 2006.

Lima, J F; Alves, L. R. Piffer, M; Piacent, C A. Análise regional das mesorregiões... 
of the secondary and tertiary activities in the mesoregions with bigger population density of the Paraná State, which are: West, Central North and Metropolitan of Curitiba. Equally, was verified that the dynamics of the State is based in the secondary and tertiary activities with prominence for the commerce and public sector.

Keywords: Regional Analysis, Regional Development, Mesoregions, Paraná state.

JEL Classification: $\mathrm{O} 18, \mathrm{R} 10, \mathrm{R} 12$.

\section{Introdução}

O objetivo deste artigo é analisar a dinâmica regional das atividades produtivas das mesorregiões do Estado do Paraná, identificando quais foram os setores que mais se destacaram e se dinamizaram no período de 1991 a 2000.

Nessa análise, a mesorregião geográfica é conceituada como a área individualizada em uma unidade da federação, que apresente formas de organização do espaço definidas pelas seguintes dimensões: as características sociais e a localização das atividades produtivas como elementos de articulação espacial. Esses elementos são construídos num processo histórico e na dinâmica regional das atividades produtivas (PIACENTI, et al., 2002). Assim, para analisar a dinâmica regional, é preciso conhecer a estrutura setorial-produtiva e verificar as transformações dessa estrutura no decorrer do tempo, que traz impacto ao seu padrão de crescimento e de desenvolvimento econômico.

$\mathrm{Na}$ análise da dinâmica regional, a região está relacionada à idéia de que áreas geográficas podem estar ligadas como um conjunto único em virtude de suas características. Estas características são as estruturas de produção, padrões de consumo, distribuição da força de trabalho e elementos culturais, sociais e políticos.

No caso paranaense, a partir dos anos 1970 , ocorreu um processo de modernização agrícola intenso, transformando-se em um dos principais exportadores de grãos do País. Nesse processo, desenvolveu-se a agroindústria, bem como um moderno complexo metal-mecânico centrado na Região Metropolitana de Curitiba. Tais transformações tecnológicas e sociais causaram profundas mudanças na estrutura espacial do Estado. Essas transformações consolidaram grandes centros, como Curitiba e Londrina, e centros secundários, como Foz do Iguaçu, Cascavel, Maringá, Guarapuava e Ponta Grossa (IPARDES, 1996).

Essas características não se formam ao acaso, pois nelas impactam a organização do espaço. A organização do espaço reflete na estrutura 
de produção agropecuária e industrial e no extrativismo e prestação de serviços. É neste sentido que essa análise busca compreender, através dos métodos de análise regional, o comportamento dos setores produtivos e como eles influenciam na dinâmica regional. De acordo com Rippel $\mathcal{E}$ Ferrera de Lima (1999), os critérios considerados na análise da região tornam-se mais amplos em virtude da inserção da estrutura produtiva na economia nacional, com todas as suas relações e impactos no crescimento econômico.

\section{Metodologia de Análise Regional}

Para análise dos dados, serão utilizadas medidas de especialização e de localização. Conforme Haddad (1989), Piacenti 83 Ferrera de Lima (2002) e Costa (2002), estas medidas são úteis para o conhecimento dos padrões do crescimento econômico das mesorregiões. Segundo Paiva (2006), a variável utilizada no modelo de análise regional leva em consideração aquela que apresente a menor possibilidade de enviesar os resultados. Por isso, a variável mais utilizada na literatura, em particular nos estudos clássicos de Isard (1972) e recentemente em Vollet $\mathcal{E}$ Dion (2001), é o número de empregados por setores. Para Paiva (2006), a restrição no uso dessa variável surge da especialização em segmentos com padrões diferenciados de uso da mão-de-obra, da mesma forma com padrões diferenciados de produtividade. Assim, seria interessante utilizar outras variáveis para complementar a análise, como, por exemplo, o valor adicionado fiscal setorial ou o valor da produção setorial das regiões. Apesar dessa restrição, a variável emprego ou mão-de-obra ocupada ainda demanda menos ajustes, principalmente de atualização monetária.

Neste contexto, a variável a ser utilizada no modelo de análise regional deste artigo será a mão-de-obra ocupada por setores de atividade. Optou-se por essa variável devido a dificuldade em coletar os dados referentes ao valor adicionado e do valor da produção setorial para o período de referência. Além disso, ao utilizar como variável a mão-de-obra setorial pressupōe-se que os setores mais dinâmicos empregam mais mão-de-obra no decorrer do tempo. Por outro lado, a ocupação da mão-de-obra reflete-se na geração e distribuição da renda regional, o que estimula o consumo e, conseqüentemente, a dinâmica da região. Os dados sobre a mão-de-obra foram coletados dos censos demográficos do Instituto Brasileiro de Geografia e Estatística (IBGE). O período-base de análise é a década de 1991, e, para efeito de análise regional, tomou-se como referência os anos de 1991 e 2000.

Outro elemento importante na análise regional e espacial é a delimitação da área de análise. Segundo Pumain e Saint-Julien (1997), 
os indicadores de análise regional, ao utilizarem o peso relativo dos setores econômicos, anulam o efeito "tamanho" das regiões. Por isso, eles permitem o cálculo de indicadores confiáveis. A área de estudo deste artigo compreende as mesorregiões do estado do Paraná, conforme demonstra a Figura 1.

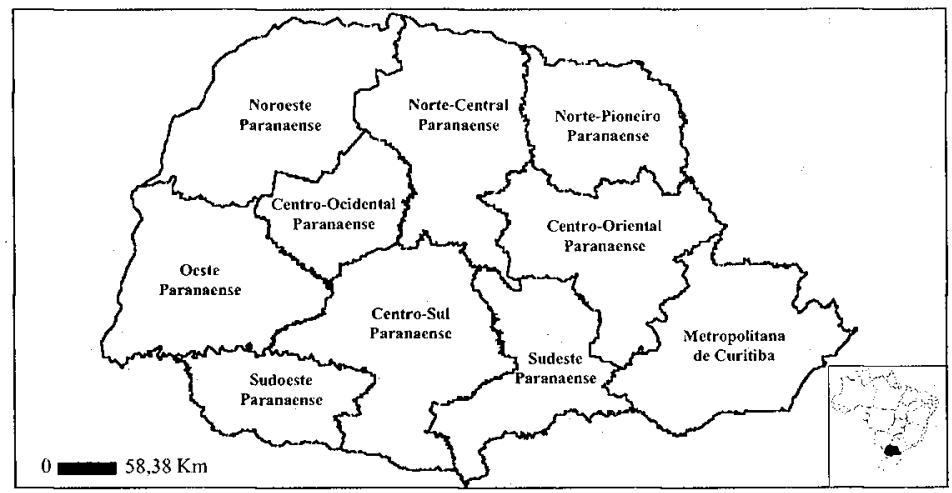

Figura 1. Mapas das mesorregiões do estado do Paraná - 2000 Fonte: IBGE, 2005.

Com a definição da variável a ser utilizada, os setores serão agrupados da seguinte forma: agropecuária (atividades agropecuárias, de extração vegetal e pesca), indústria da transformação, indústrias da construção civil, outras atividades industriais (extração mineral e serviços industriais de utilidade pública), transportes e comunicações, comércio de mercadorias, serviços (alojamento e alimentação, reparação e conservação, pessoais, domiciliares, diversões, auxiliares das atividades econômicas, técnicos profissionais, atividades sociais e outras atividades que não se enquadram nas demais categorias) e setor público (administração pública, defesa nacional e segurança pública).

Para o cálculo das medidas de especialização e localização, as informações serão organizadas em uma matriz que relaciona a distribuição setorial-espacial de uma variável-base. No presente estudo, utilizar-se-á a mão-de-obra ocupada por setores de atividade como variável-base. As colunas mostram a distribuição da mão-de-obra entre as mesorregiões e as linhas mostram a distribuição da mão-deobra por setor de cada uma das mesorregiões. A partir dessa distribuição, têm-se as seguintes equações:

$$
E_{i j}=\text { Mão-de-obra no setor } i \text { da mesorregião j; }
$$

$\sum_{j} E_{i j}=$ Mão-de-obra no setor $i$ de todas as mesorregiões; 
$\sum_{i} E_{i j}=$ Mão-de-obra em todos os setores da mesorregião j;

$\sum_{i} \sum_{j} E_{i j}=$ Mão-de-obra em todos os setores e todas as mesorregiões.

A partir das equações (1, 2, 3 e 4) organiza-se a Tabela 1 , que apresenta as medidas de localização e especialização. As medidas de localização (Quociente Locacional, Coeficiente de Localização, Coeficiente de Associação Geográfica e Coeficiente de Redistribuição) são de natureza setorial e se preocupam com a localização das atividades entre as mesorregiões, ou seja, procuram identificar padrões de concentração ou dispersão da mão-de-obra setorial num determinado período. Já as medidas de especialização concentram-se na análise da estrutura produtiva de cada mesorregião, objetivando analisar o grau de especialização das economias regionais num determinado período. Dentre estas medidas, utilizar-se-á o Coeficiente de Especialização e o Coeficiente de Reestruturação.

Tabela 1. Descrição das medidas de localização, especialização e associação geográfica

\begin{tabular}{|c|c|c|}
\hline Indicador & Equação & Interpretação dos Resultados \\
\hline $\begin{array}{l}\text { Quociente } \\
\text { Locacional (QL) }\end{array}$ & $Q L_{i j}=\frac{E_{i j} / \sum_{j} E_{i j}}{\sum_{i} E_{i j} / \sum_{i} \sum_{j} E_{i j}}$ & $\begin{array}{c}Q L \geq 1 / \text { localização significativa } \\
0,50 \leq Q \mathrm{QL} \leq 0,99 / \text { localização média } \\
\mathrm{QL} \leq 0,49 / \text { localização fraca }\end{array}$ \\
\hline $\begin{array}{l}\text { Coeficiente de } \\
\text { Localização (CL) }\end{array}$ & $C L_{i}=\frac{\sum_{j} \|\left(E_{i j} / \sum_{j} E_{i j}\right)-\left(\sum_{i} E_{i j} / \sum_{i} \sum_{j} E_{i j}\right)}{2}$ & $\begin{array}{l}\text { Próximo a } 0=\text { dispersão significativa } \\
\text { Próximo a } 1=\text { concentração significativa }\end{array}$ \\
\hline $\begin{array}{l}\text { Coeficiente de } \\
\text { Especialização (CE) }\end{array}$ & $C E s p_{j}=\frac{\sum_{i} \mid\left(E_{i j} / \sum_{i} E_{i j}\right)-\left(\sum_{j} E_{i j} / \sum_{i} \sum_{j} E_{i j}\right.}{2}$ & $\begin{array}{l}\text { Próximo a } 0=\text { diversificação significativa } \\
\text { Próximo a } 1=\text { especialização significativa }\end{array}$ \\
\hline $\begin{array}{l}\text { Coeficiente de } \\
\text { Associação } \\
\text { Geográfica (Cag) }\end{array}$ & $C a g_{i k}=\frac{\sum_{j}\left(\mid\left(E_{i j} / \sum_{i}^{\text {setor }} E_{i j}\right)-\left(E_{i j} / \sum_{i} E_{i j}\right)\right)}{2}$ & $\begin{array}{c}0,35 \leq \mathrm{Cag} \leq 0,00=\text { associação significativa } \\
0,69 \leq \mathrm{Cag} \leq 0,34=\text { associação média } \\
1,04 \leq \mathrm{Cag} \leq 0,68=\text { fraca associação }\end{array}$ \\
\hline $\begin{array}{l}\text { Coeficiente de } \\
\text { Reestruturação-Cr }\end{array}$ & $C r=\frac{\sum_{i}\left|\left(E_{i j} / \sum_{i} E_{i j}\right)-\left(E_{i j} / \sum_{i} E_{i j}\right)\right|}{2}$ & $\begin{array}{l}\text { Próximo a } 0=\text { reestruturação não significativa } \\
\text { Próximo a } 1=\text { reestruturação significativa }\end{array}$ \\
\hline $\begin{array}{l}\text { Coeficiente de } \\
\text { Redistribuição } \\
\text { CRÉD }\end{array}$ & $\mid \frac{\left.11 / \sum_{j} E_{i j}\right)-\left(E_{i j} / \sum_{j} E_{i j}\right) \mid}{2}$ & $\begin{array}{l}\text { Próximo a } 0=\text { distribuição não significativa } \\
\text { Próximo a } 1=\text { distribuição significativa }\end{array}$ \\
\hline
\end{tabular}

Fonte: Piac rrera de Lima et. al. (2004) e Ferrera de Lima (2006). 
O Quociente Locacional é utilizado para comparar a participação percentual da mão-de-obra de uma mesorregião com a participação percentual no total do estado. O quociente locacional pode ser analisado a partir de setores específicos ou no seu conjunto. A importância da mesorregião no contexto estadual, em relação ao setor estudado, é demonstrada quando o $\mathrm{QL}$ assume valores $\geq 1$. Como o quociente é medido a partir de informações da mão-de-obra $(E)$, pode-se verificar os setores que possuem possibilidades para atividades de exportação inter-regionais.

O objetivo do coeficiente de localização é relacionar a distribuição percentual da mão-de-obra num dado setor entre as mesorregiões, com a distribuição percentual da mão-de-obra do estado. Se o coeficiente de localização for igual a zero (0), significa que o setor i estará distribuído regionalmente da mesma forma que o conjunto de todos os setores. Se o valor for igual a um (1), demonstrará que o setor $i$ apresenta um padrão de concentração regional mais intenso do que o conjunto de todos os setores.

O coeficiente de especialização é uma medida regional. As medidas regionais concentram-se na estrutura produtiva de cada mesorregião, fornecendo informações sobre o nível de especialização da economia num período. Através do coeficiente de especialização, compara-se a economia de uma mesorregião com a economia do estado como um todo. Para resultados iguais a 0 (zero), a mesorregião tem composição idêntica à do estado. Em contrapartida, coeficientes iguais ou próximos a 1 demonstram um elevado grau de especialização ligado a um determinado setor, ou uma estrutura de mão-de-obra totalmente diversa da estrutura de mão-de-obra regional.

O coeficiente de associação geográfica mostra a associação geográfica entre dois setores ( $i$ e $k$ ), comparando as distribuições percentuais da mão-de-obra entre as mesorregiōes. Seus valores variam de zero (0), que significa que o setor $i$ estará distribuído regionalmente da mesma forma que o setor $k$, mostrando que os padrões locacionais dos dois setores estão associados geograficamente, até um (1), que representa nenhuma associação.

O coeficiente de reestruturação relaciona a estrutura de mão-deobra por mesorregião entre dois períodos, ano base 0 e ano 1 (1980 e 2000), objetivando verificar o grau de mudanças na especialização das mesorregiões que compóem o Estado. Coeficientes iguais a zero (0) indicaṃ que não ocorreram modificações na estrutura setorial da mesorregião, e iguais a um (1) demonstram uma reestruturação bem substancial.

O coeficiente de redistribuição relaciona a distribuição percentual de emprego de um mesmo setor em dois períodos, ano base 0 e ano 1 
(1991 e 2000), objetivando verificar se está prevalecendo para o setor algum padrão de concentração ou dispersão espacial ao longo do tempo. Coeficientes próximos a zero $(0)$ indicam que não ocorreram mudanças significativas no padrão espacial de localização do setor, e próximos a um (1) demonstram que ocorreram mudanças no padrão espacial de localização do setor.

\subsection{0 modelo diferencial e estrutural}

A partir dos resultados do QL, será possivel identificar os setores básicos $(\mathrm{QL}>1)$ e não-básicos $(\mathrm{QL}<1)$, ou seja, aqueles que possuem atividades de exportação ou não. No entanto, resta saber se esses setores foram responsáveis pelo crescimento econômico das mesorregiões. Para isso, é necessário analisar a variação e o deslocamento da mão-de-obra ocupada, no período estudado, entre os setores básicos e não-básicos. Assim, utilizando-se a matriz da distribuição espacial da mãode-obra setorial, chega-se à equação à seguir:

$$
\left.V L T_{i j}=\left(\begin{array}{c}
A n o 2 \\
E_{i j}-E_{i j}
\end{array}\right)-E_{i j}\left(\sum_{i} \sum_{j}^{A n o 2} E_{i j} / \sum_{i} \sum_{j}^{A n o 1} E_{i j}\right)-1\right)
$$

onde:

VLT = Variação Liquida Total da MO

Ano $1=1991$

Ano $2=2000$

$\mathrm{MO}=$ Mão-de-obra ocupada por ramos de atividade

A VLT indicará a diferença entre o valor real da mão-de-obra entre o início (1991) e no fim do período (2000). Quando seu valor for positivo, significa que houve um incremento relativo da ocupação mesorregional de mão-de-obra face à ocupação estadual. Ao contrário, quando o valor da VLT for negativo, representa uma perda de posição relativa. Com isso, a magnitude do valor positivo demonstra o "peso" significativo do setor na dinâmica do emprego nas mesorregiōes. Dessa forma, se os ramos básicos tiverem os valores positivos mais signifiçativos, o que corresponde a uma estrutura de exportação dinâmica, então, os fatores exógenos são os responsáveis pelo crescimento econômico mesorregional. Vale lembrar que a VLT é a diferença entre a parcela regional com a parcela estrutural. A primeira refere-se aos fatores diferenciais, ou seja, reflete a especialização regional de um determinado setor (endógeno). A segunda representa os fatores estruturais, refletindo a composição regional da ocupação (exógenos). As. sim, essa diferença entre a composição regional e a estrutural recebe o nome de efeito total, ou seja, variação líquida total. 
A parcela regional e a parcela estrutural, ou seja, os fatores endógenos e exógenos supracitados, podem ser calculados separadamente a partir da decomposição da VLT em duas parcelas. Essas parcelas recebem o nome de variação líquida diferencial, ou regional (VLD), e variação líquida proporcional, ou estrutural (VLP).

Segundo os estudos de Lodder (1974), e recentemente Ferrera de Lima (2006), o efeito diferencial ou regional (VLD) reflete o dinamismo que cada setor possui dentro da mesorregião. A VLD parte da constatação de que existem alguns setores que se expandem mais rapidamente que a média estadual do setor. A VLD está representada pela equação 6.

$$
V L D_{i j}=E_{i j}^{A n o 1}\left(\left(\begin{array}{c}
A n o 2 \\
E_{i j}
\end{array} / \begin{array}{c}
A n o 1 \\
E_{i j}
\end{array}\right)-\left(\sum_{j}^{A n o 2} E_{i j} / \sum_{j}^{A n o 1} E_{i j}\right)\right)
$$

onde:

VLD = Variação Liquida Diferencial da MO

Ano $1=1991$

Ano $2=2000$

MO = Mão-de-obra ocupada por ramos de atividade

A VLD positiva indica os setores mais especializados de cada mesorregião. Por isso, essa especialização é explicada também pela existência de economias de aglomeração de cada mesorregião, resultantes de um conjunto de elementos que favorecem o crescimento regional, ou seja, regiões que possuem vantagens locacionais com respeito a cada setor e melhoram sua capacidade de atração (FERRERA DE LIMA, 2006).

O efeito estrutural ou proporcional (VLP) reflete a composição regional da ocupação, concentrada em setores economicamente dinâmicos. A VLP está representada pela equação 7.

$$
V L P_{i j}=E_{i j}^{A n o 1}\left(\left(\sum_{j}^{A n O 2} E_{i j} / \sum_{j}^{A n o 1} E_{i j}\right)-\left(\sum_{i} \sum_{j}^{A n o 2} E_{i j} / \sum_{i} \sum_{j}^{A n o 1} E_{i j}\right)\right)
$$

onde:

VLP = Variação Liquida Proporcional da MO

Ano $1=1991$

Ano $2=2000$

MO = Mão-de-obra ocupada por ramos de atividade

Dessa forma, uma VLP positiva indica uma conce ıtração da estrutura ocupacional da mesorregião em setores de forte crescimento, 
principalmente em função dos ciclos produtivos regionais e da sua capacidade de dinamizar as atividades produtivas, enquanto a VLP negativa indica uma economia baseada em setores não-dinâmicos (LODDER, 1974; FERRERA DE LIMA, 2006).

\section{Análise dos resultados}

A seguir, são apresentados os resultados obtidos com a aplicação da metodologia de análise regional, através das medidas de especialização e localização. Na Tabela 2, consta a distribuição percentual da mão-de-obra entre as mesorregiões do Estado do Paraná.

Tabela 2. Distribuição percentual da mão-de-obra setorial entre as microrregiões do estado de Paraná - 1991/2000

\begin{tabular}{|c|c|c|c|c|c|c|c|c|c|c|c|c|c|c|c|c|}
\hline \multirow[t]{2}{*}{ Mesorregiós } & \multicolumn{2}{|c|}{ A gropectuária } & \multicolumn{2}{|c|}{$\begin{array}{c}\text { Ind dat } \\
\text { irans formaçào }\end{array}$} & \multicolumn{2}{|c|}{$\begin{array}{l}\text { Ind da } \\
\text { construçăo } \\
\text { civil }\end{array}$} & \multicolumn{2}{|c|}{$\begin{array}{l}\text { Outras } \\
\text { Atividades } \\
\text { industrials }\end{array}$} & \multicolumn{2}{|c|}{$\begin{array}{l}\text { Transportes e } \\
\text { comunicaçòes }\end{array}$} & \multicolumn{2}{|c|}{ Connercio } & \multicolumn{2}{|c|}{ Serviços } & \multicolumn{2}{|c|}{ Setor público } \\
\hline & 1991 & 2000 & 1991 & 2000 & 1991 & 2000 & 1991 & 2000 & 1991 & 2000 & 1991 & 2000 & 1991 & 2000 & 1991 & 2000 \\
\hline Centro Ocidental & 7,36 & 5,52 & 239 & 2,20 & 3,05 & 2,51 & 3,81 & 252 & 2,76 & 38 & 396 & 3,21 & 3,59 & 2,92 & $3, \overline{40}$ & 3,30 \\
\hline Sudeste & 8,20 & 9.30 & 3.97 & 3.69 & 2,40 & 2.83 & 2,54 & 2,91 & 2,57 & 1.99 & 1.95 & 2,30 & 2,29 & 2,33 & 3,30 & 2,64 \\
\hline Norte Pioneiro & 10,10 & 10,19 & 4,07 & 4,01 & 4,95 & 4,84 & 7,33 & 6.30 & 3,80 & 3,12 & 4.87 & 4.32 & 5,41 & 4.64 & 6,36 & 5,12 \\
\hline Centro-Su & 9,44 & 9,97 & 4.77 & 4,39 & 5.17 & 4,60 & 426 & 5.42 & 3,96 & 3,84 & 3,63 & 3.85 & 3,62 & 3.69 & 3.81 & 4,00 \\
\hline Oeste & 12,24 & 12,61 & 7.45 & 9.59 & 11.85 & 11,13 & 15.05 & 15.71 & 10.93 & 14,71 & 14,62 & 14,19 & 11,97 & 12,06 & 10,16 & 11,14 \\
\hline Norte $C$ & 17,11 & 16,23 & 22.57 & 23.21 & 21.48 & 19,96 & 16,12 & 13.08 & 19.68 & 18,13 & 24.11 & 2132 & 22,10 & 20,55 & 19,06 & 19,90 \\
\hline Metropolicaua & 7.00 & 8.69 & 38.27 & 35,09 & 34.71 & 38,19 & 32,35 & 38.60 & 39,49 & 41.70 & 31.17 & 35.31 & 35.36 & 39.08 & 35,33 & 37.86 \\
\hline
\end{tabular}

Fonte: IBGE, censos demográficos, vários volumes.

Pelos dados da Tabela 2, a mesorregião Metropolitana de Curitiba concentra a grande maioria da mão-de-obra do Estado, com exceção do setor agropecuário. Em segundo lugar, é a mesorregião norte central que se destaca. Em terceiro, a mesorregião Oeste. Estas três mesorregiões têm a maioria dos empregados em todos os setores analisados e na hierarquia anteriormente apresentada. No geral, é o setor da agropecuária o mais distribuído entre as mesorregiões do Paraná. Os demais setores apresentam um grau de concentração mais intenso nas três mesorregiōes anteriormente mencionadas.

A mesorregião Metropolitana de Curitiba é mais dinâmica do estado, concentrando cerca de um terço da população e manifestando fortes indicativos de continuidade. Embora apresente diversidades em sua paisagem, é comandada por um processo de crescimento, que, diferentemente das demais mesorregiōes paranaenses, decorre de atividades dos segmentos modernos de produção (IPEA, 2000).

Os setores que apresentaram maiores possibilidades para atividades de exportação são analisados através dos indicadores do quociente locacional (Figura 2), e nota-se que no Paraná o setor da agropecuária está mais difuso entre as mesorregiões, sendo o setor mais 
significativo do Estado. Cabendo às mesorregiões Noroeste, Centro Ocidental, Norte Pioneiro, Oeste, Sudeste, Sudoeste e Centro Sul os maiores valores deste setor, caracterizando uma maior concentração de suas atividades produtivas. No entanto, outros setores se destacaram no Estado: os setores das atividades industriais concentram-se fundamentalmente na regiāo entre as mesorregiōes Norte Central e Metropolitana de Curitiba. A mesorregião Oeste se destaca no setor de outras atividades industriais.

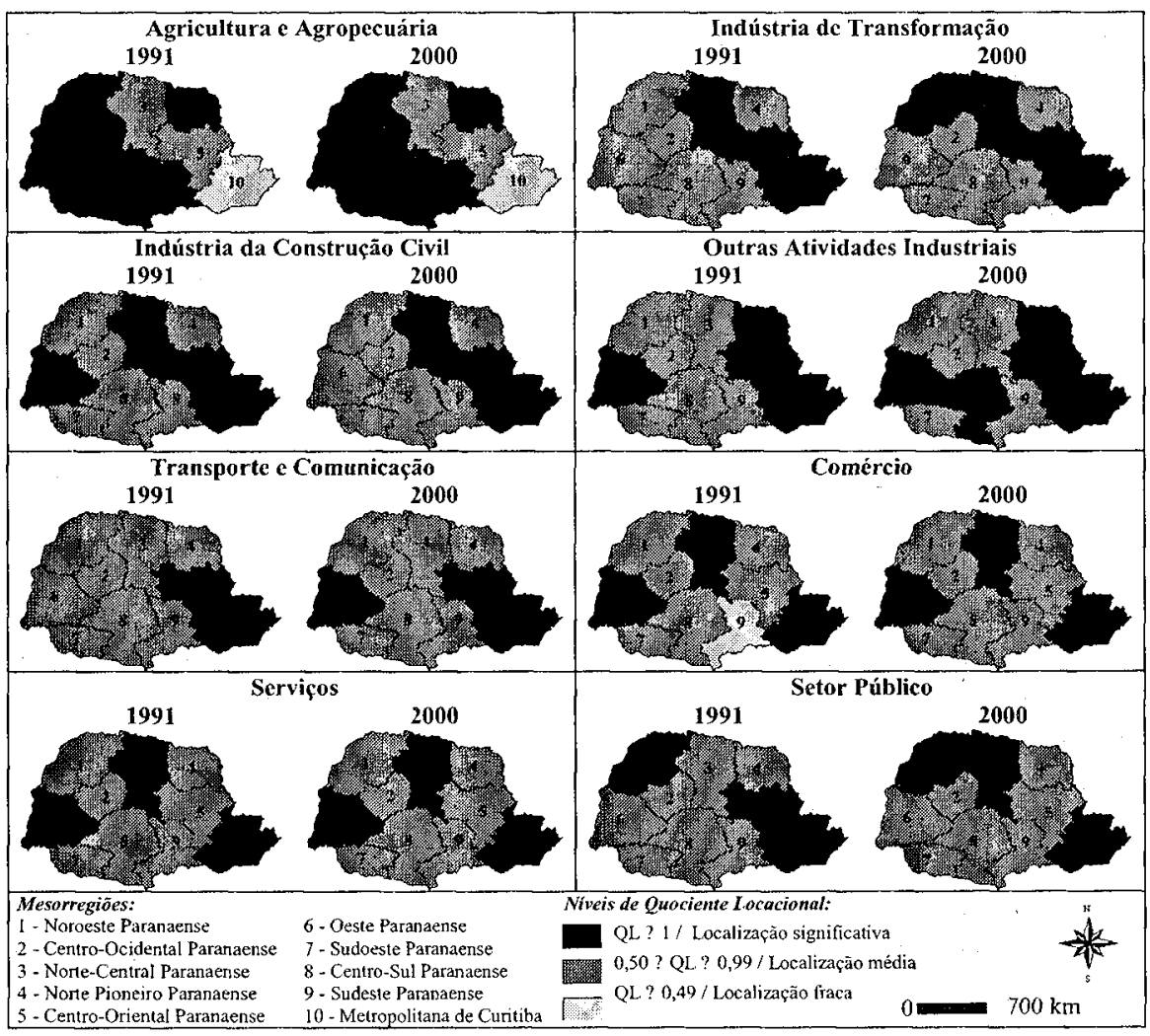

Figura 2. Quociente locacional das mesorregiões do estado do Paraná $1991 / 2000$

Fonte: Resultados da Pesquisa

O setor terciário, formado pelos ramos comercial e de serviços, apresentou localizaçāo significativa nas mesorregiões Oeste, Norte Central e Metropolitana de Curitiba em ambos os anos analisados. Essa característica pode ser explicada, em parte, por essas três mesorregiões serem formadas pelas principais metrópoles do estado, ou seja, a intensa urbanização. Nesse caso, o resultado do indicador confirma 
a tendência da economia regional de deslocar-se para as atividades terciárias, à medida que seu perfil de desenvolvimento vai amadurecendo e a mão-de-obra se adensando.

O setor de transporte e comunicação chegou no ano de 2000 apresentando localização significativa nas mesorregiōes Oeste, Centro Oriental e Metropolitana de Curitiba. Os principais corredores rodoviários do Estado passam por essas três mesorregiões, explicando, assim, parte dessa localização significativa.

Nota-se, pela Figura 2, a formação de um corredor da indústria de transformação. Esse corredor começa na mesorregião Noroeste Paranaense, englobando as mesorregiões Norte-Central, Centro-Oriental e a Metropolitana de Curitiba. Deve-se salientar que o Noroeste Paranaense entrou nesse corredor em 2000. Já as outras atividades industriais envolveram três mesorregiões periféricas no setor da indústria de transformação: a Oeste, a Norte-Pioneiro e a Centro-Sul.

No contexto geral, a análise do QL demonstra a "periferização" das mesorregiões Sudoeste, Norte Pioneiro, Sudeste, Centro-Ocidental e Centro-Sul Paranaenses. Essas mesorregióes apresentaram poucas localizaçōes significativas no período analisado.

Já, no Gráfico 1, observa-se o coeficiente de localização dos setores em destaque.

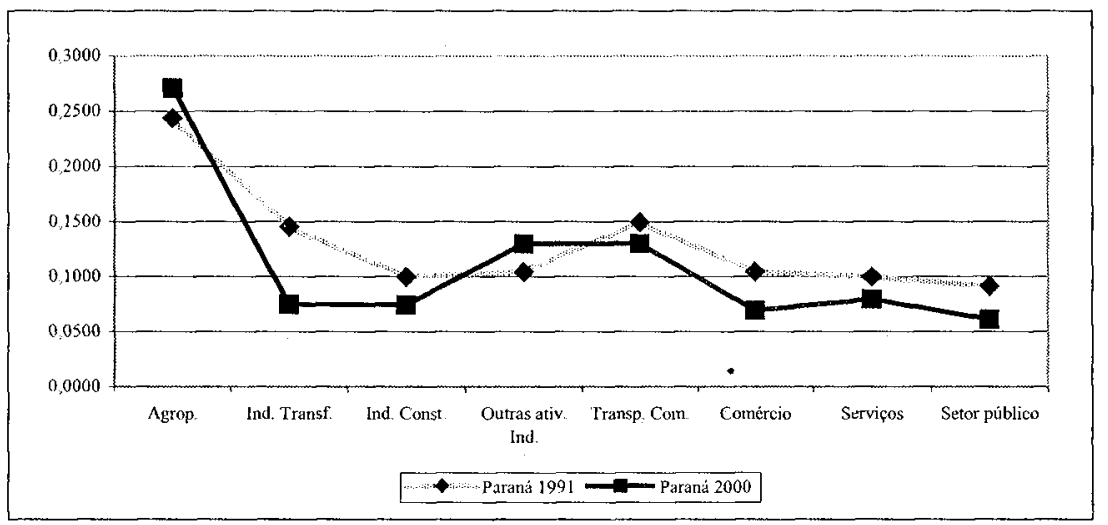

Gráfico 1. Coeficiente de localização dos setores do estado do Paraná $1991 / 2000$

Fonte: Resultados da Pesquisa

Notou-se pelo coeficiente de localização que em 1991 eram os setores de serviços, público, indústria da construção, comercial e de outras atividades industrias que estavam mais distribuídos. Os setores da agropecuária e de transporte e comunicação estavam mais concentrados. Já no ano de 2000 , os setores que apresentavam uma 
distribuição mais significativa eram a indústria de transformação, a indústria da construção, o comércio, os serviços e o setor público. Os setores da agropecuária e de transporte e comunicação continuam sendo os mais concentrados, mas nota-se que o setor de outras atividades industriais teve seu coeficiente de concentração elevado nesse período. No geral, foi o setor público o mais distribuído e o setor agropecuário o mais concentrado.

No Gráfico 2, é possível notar o coeficiente de redistribuição dos setores analisados.

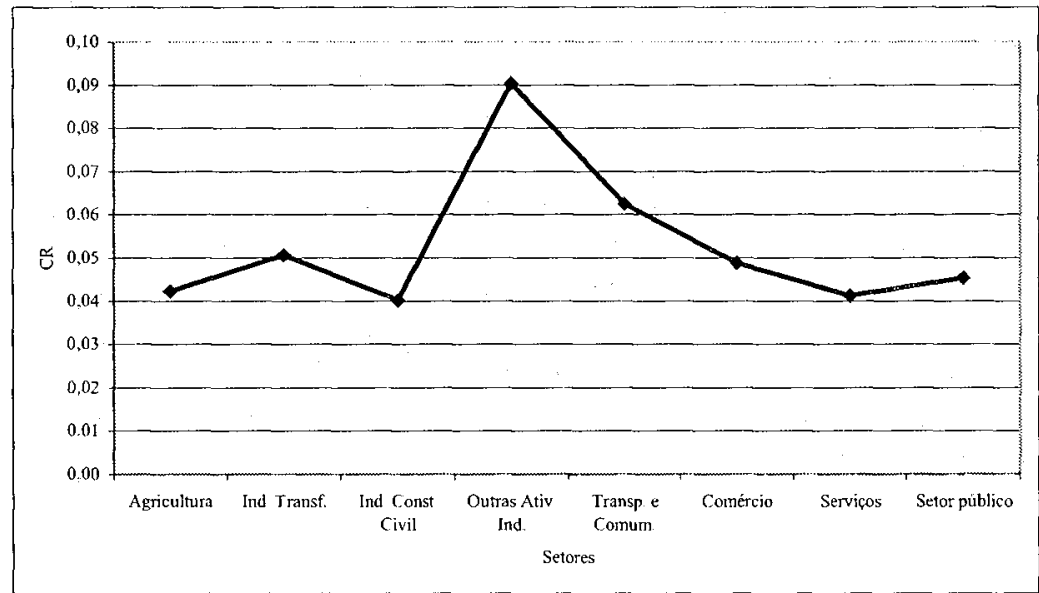

Gráfico 2. Coeficiente de redistribuição dos setores do estado do Paraná $1991 / 2000$

Fonte: Resultados da Pesquisa

Pelo Gráfico 2, os setores de outras atividades industrias, transporte e comunicação apresentaram um grau de distribuição mais significativo no período analisado. O setor de outras atividades industriais é composto pela extração mineral e pelos serviços industriais de utilidade pública, o que demonstra uma melhor distribuição dessas atividades. Os demais setores não demonstraram significância na distribuição espacial ao longo do tempo, ou seja, as mesmas mesorregiões que apresentavam localização significativa no ano de 1991 continuaram apreșentando no ano de 2000 , sem alterações representativas.

Já no Gráfico 3, é apresentado o coeficiente de especialização, ou seja, o comportamento da especialização das mesorregiões em relação ao Estado.

Pode-se observar, pelo Gráfico 3, que as mesorregiões Sudeste e Sudoeste Paranaense apresentaram um grau de especialização mais intenso que as demais no ano de 1991 e no ano de 2000. Nesse 
caso, elas estão com um grau de especialização elevado em atividades ligadas a um ou mais setores. Analisando o quociente locacional para essas duas mesorregiōes verifica-se que somente o setor agropecuário apresentou localização significativa, e isso explica um coeficiente de especialização mais elevado. Já as mesorregiōes com um grau de diversificação mais intenso em todo o período foram: Oeste, Norte Central e Centro Oriental Paranaense.

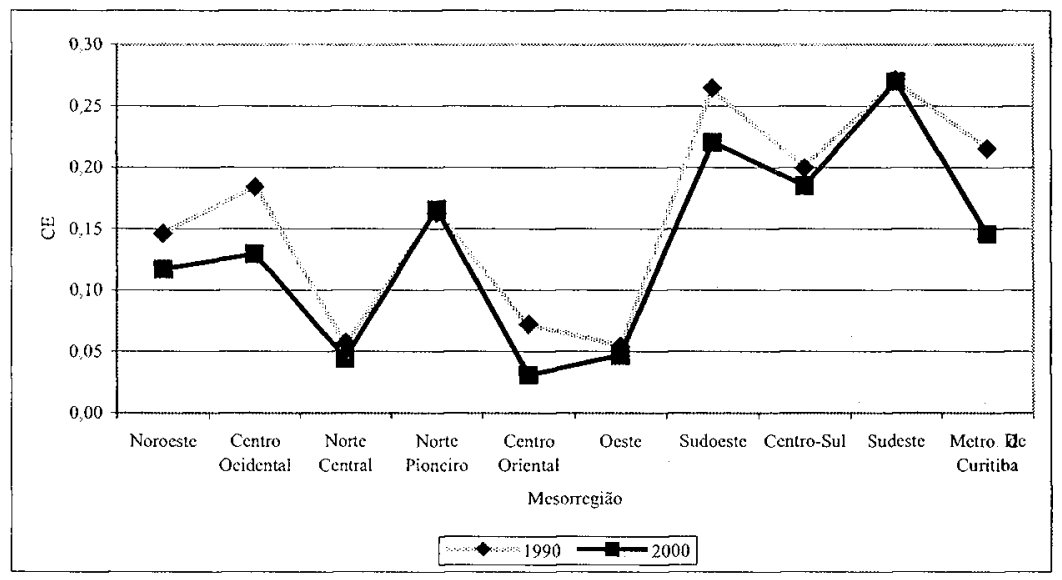

Gráfico 3. Coeficiente de especialização das mesorregiōes do estado do Paraná - 1991/2000

Fonte: Resultados da Pesquisa

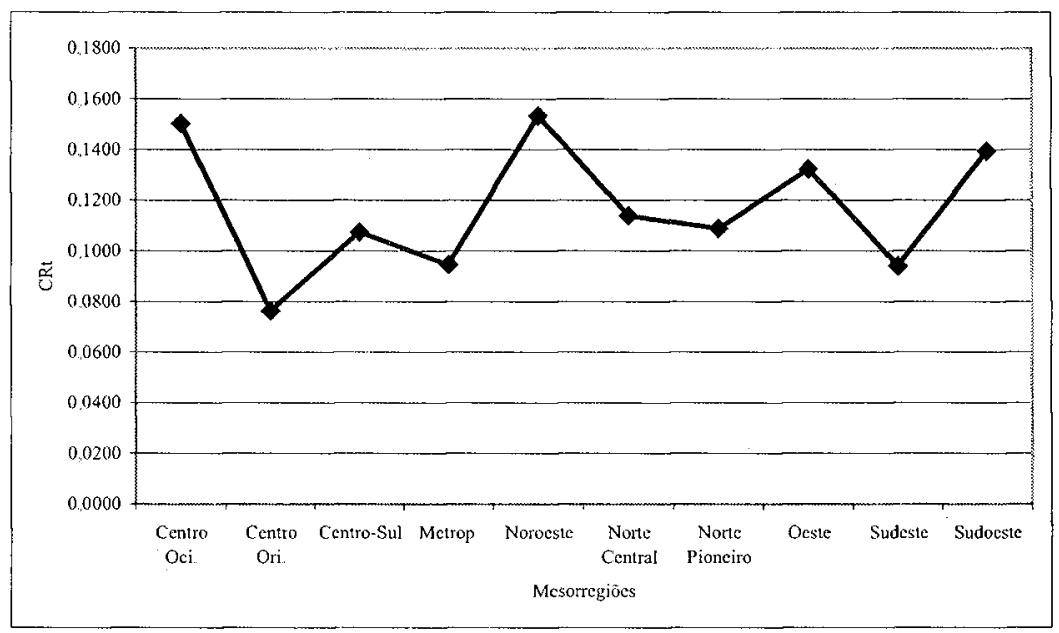

Gráfico 4. Coeficiente de reestruturação das mesorregiões do estado do Paraná $-1991 / 2000$

Fonte: Resultados da Pesquisa

Lima, J. F; Alves, L. R; Piffer, M; Piacent, C A Análise regional das mesorregiões... 
Pelo Gráfico 4, pode-se verificar o coeficiente de reestruturação das mesorregiões do Estado do Paraná.

$O$ coeficiente de reestruturação mostra que as mesorregiões Centro Ocidental, Noroeste e Oeste Paranaense apresentaram os valores mais elevados, mostrando que nestas mesorregiões ocorreu uma reestruturação na composição setorial mais significativa. O contrário ocorreu com as demais mesorregióes. A Figura 2 a seguir apresenta o coeficiente de associação geográfica.

\begin{tabular}{|c|c|c|c|c|c|c|c|c|c|c|c|c|c|c|c|c|}
\hline \multirow[t]{2}{*}{ Regiôes } & \multicolumn{2}{|c|}{ Agropecuária } & \multicolumn{2}{|c|}{$\begin{array}{l}\text { Industria da } \\
\text { transformaçăo }\end{array}$} & \multicolumn{2}{|c|}{$\begin{array}{c}\text { Industrias da } \\
\text { construção } \\
\text { civil }\end{array}$} & \multicolumn{2}{|c|}{$\begin{array}{c}\text { Outras } \\
\text { atividades } \\
\text { industriais }\end{array}$} & \multicolumn{2}{|c|}{$\begin{array}{r}\text { Transportes e } \\
\text { comunicações }\end{array}$} & \multicolumn{2}{|c|}{ Comércio } & \multicolumn{2}{|c|}{ Serviços } & \multicolumn{2}{|c|}{ Setor püblico } \\
\hline & 1991 & 2000 & 1991 & 2000 & 1991 & 2000 & 1991 & 2000 & 1991 & 2000 & 1991 & 2000 & 1991 & 2000 & 1991 & 2000 \\
\hline Agropecuária & + & + & & & & & & & & & & & & & & \\
\hline Ind. Transf. & 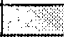 & $\sqrt{270}$ & - & $\bullet$ & & & & & & & & & & & & \\
\hline Ind. Const. Civil & $\sqrt{2}$ & (3) & & & - & 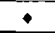 & & & & & & & & & & \\
\hline Outras Ativ. Ind. & 1.1 & 8 & & & & & + & + & & & & & & & & \\
\hline Transp. c Comum. & & 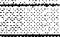 & & & & & & & + & - & & & & & & \\
\hline Comércio & 1 & & & & & & & & & & - & + & & & & \\
\hline Serviços & & ? & & & & & & & & & . & & + & 4 & & \\
\hline Setor dúblico & 18 & 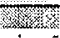 & & & & & & & & . & & & & & 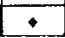 & - \\
\hline
\end{tabular}

Figura 3. Coeficiente de associaçăo geográfica das mesorregiões da estado do Paraná - 1991/2000

Fonte: Resultados da Pesquisa

Pela Figura 3, nota-se que no ano de 1991 e 2000 os setores secundário e terciário apresentaram associação significativa entre si em todo o período, ou seja, os padrōes locacionais desses setores estão associados geograficamente. Somente o setor agropecuário não apresentou associação significativa com nenhum outro setor. No entanto, nota-se que o setor agropecuário elevou seu coeficiente de associação com o setor da indústria de transformação. As várias indústrias de transformação agroalimentar instaladas no estado nesse período podem explicar, em parte, o aumento do coeficiente.

\subsection{Análise diferencial-estrutural (Shift and Share)}

A análise shift and share auxilia na compreensão da dinâmica setorial, ao indicar os setores responsáveis por essa dinâmica. Na Figura 4, são apresentados os índices de Variação Líquida Proporcional (VLP).

Uma VLP positiva indica uma concentração da estrutura ocupacional da mesorregião em setores de alto dinamismo. 


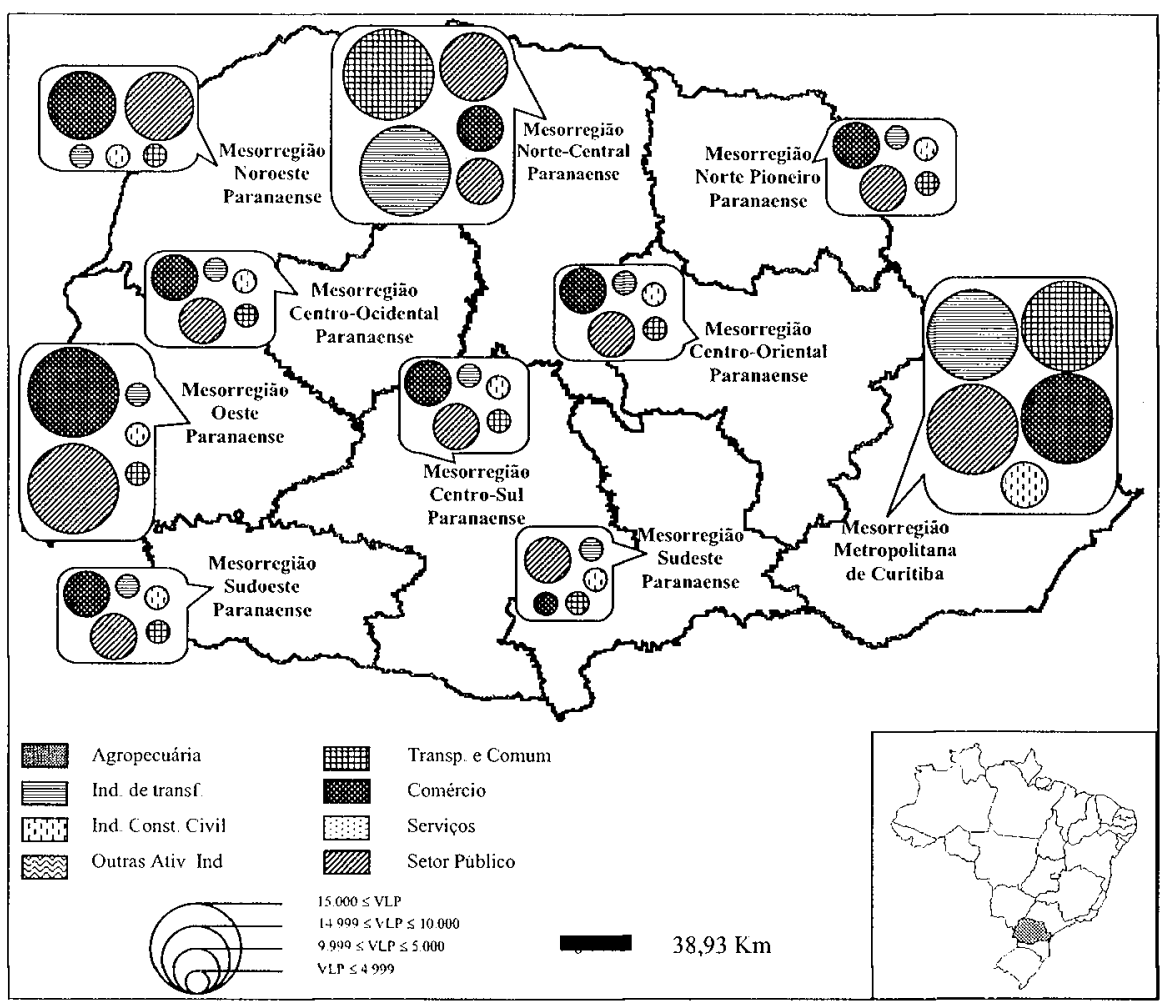

Figura 4. Variação liquida proporcional (VLP) positiva das mesorregiões do estado do Paraná - 1991/2000

Fonte: Resultados da Pesquisa

Notou-se pela Figura 4 que os setores da indústria de transformação, da indústria da construção civil, de transporte e comunicação, de comércio e o setor público apresentaram valores positivos para todas as mesorregiões do Paraná. As mesorregiões que mais se destacaram foram: Oeste, Norte Central e Metropolitana de Curitiba, pois apresentaram os maiores valores para a VLP. Assim, os setores supracitados foram os mais dinâmicos entre as mesorregiões paranaenses no período analisado.

Já na Figura 5 apresenta a VLD. Através da VLD é possivel notar o dinamismo que cada setor possui dentro da região, haja vista que a diversidade de taxas de crescimento regional deriva do fato de que certos setores crescem mais rapidamente em uma região do que em outra. Os valores positivos mostrarão que as mesorregiões alcançaram maiores vantagens locacionais com respeito a tais atividades. 


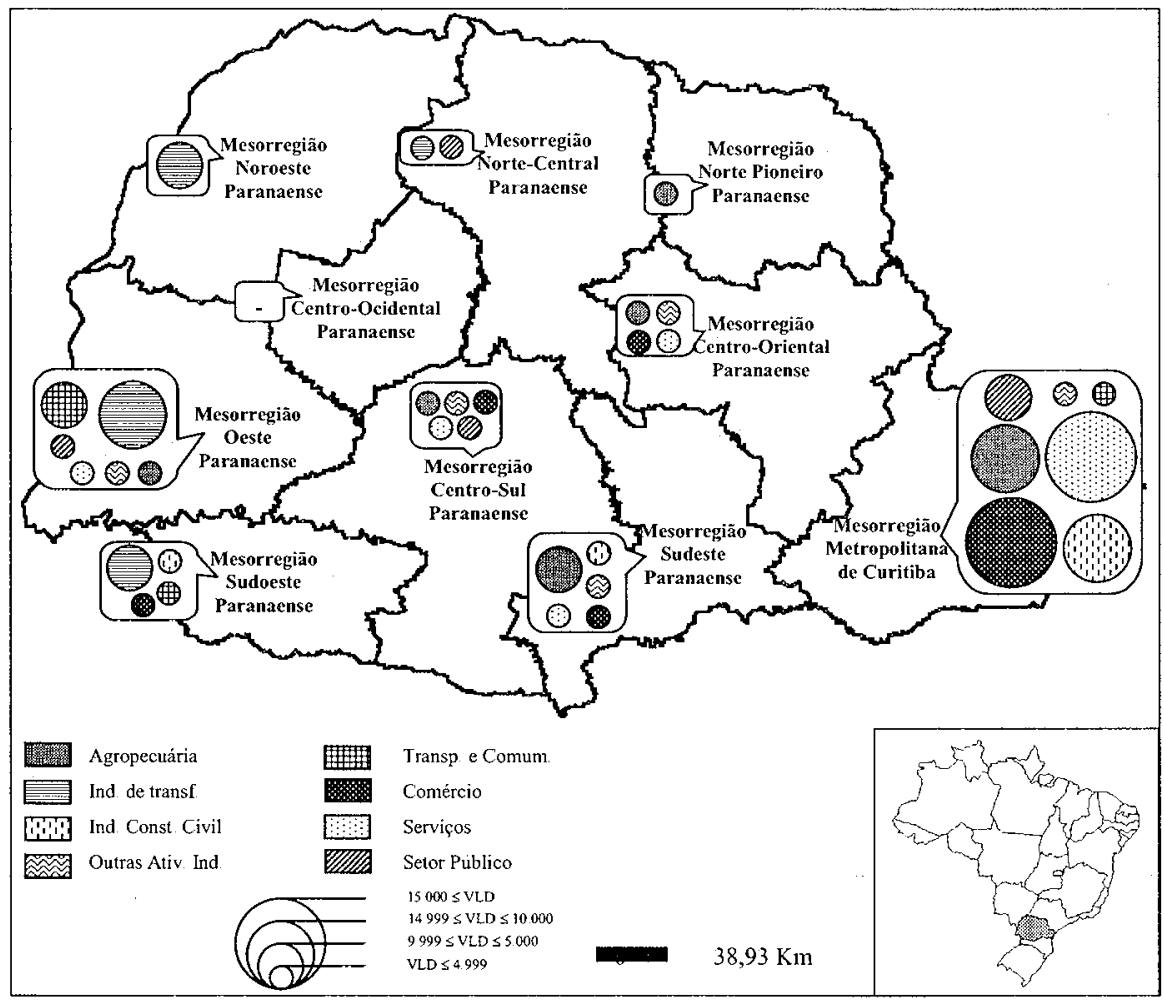

Figura 5. Variação liquida diferencial (VLD) positiva das mesorregiões do estado do Paraná - 1991/2000

Fonte: Resultados da Pesquisa

Neste pressuposto, notou-se, pela Figura 5, que a mesorregião Centro Ocidental não apresentou nenhum setor com valores positivos, ou seja, os setores analisados não são especializados nessa mesorregião, não existindo, assim, vantagens locacionais dos setores aqui analisados. No geral, nas demais mesorregiōes o setor mais distribuído espacialmente foi o agropecuário, demonstrando uma forte especialização e dependência da maioria das mesorregiões nesse setor. Outrossim, os setores de outras atividades industriais, comércio e serviços também apresentaram valores positivos em várias mesorregiões. Os setores de comércio e serviços são mais especializados na mesorregião Metropolitana de Curitiba. Já o setor da indústria de transformação, nas mesorregiōes Oeste, Sudoeste e Noroeste. Na Figura 6, verificaremos o resultado da variação líquida total (VLT). Através da VLT, que nada mais é do que o somatório da VLP com a VLD, pode-se verificar quais são os setores que mais se dinamizaram no período estudado. 
Observa-se que os setores do comércio e o público apresentaram valores positivos para todas as mesorregiões. Assim, esses dois setores foram dinâmicos no período analisado em todo o Estado. Os setores da indústria da transformação, da indústria da construção civil e de transporte e comunicação se destacam na maioria das mesorregiōes. O setor de serviços apresentou valores positivos somente na mesorregião Metropolitana de Curitiba. Os setores da agropecuária e de outras atividades industriais não apresentaram valores positivos, mostrando que esses setores não foram dinamizados nas mesorregiões.

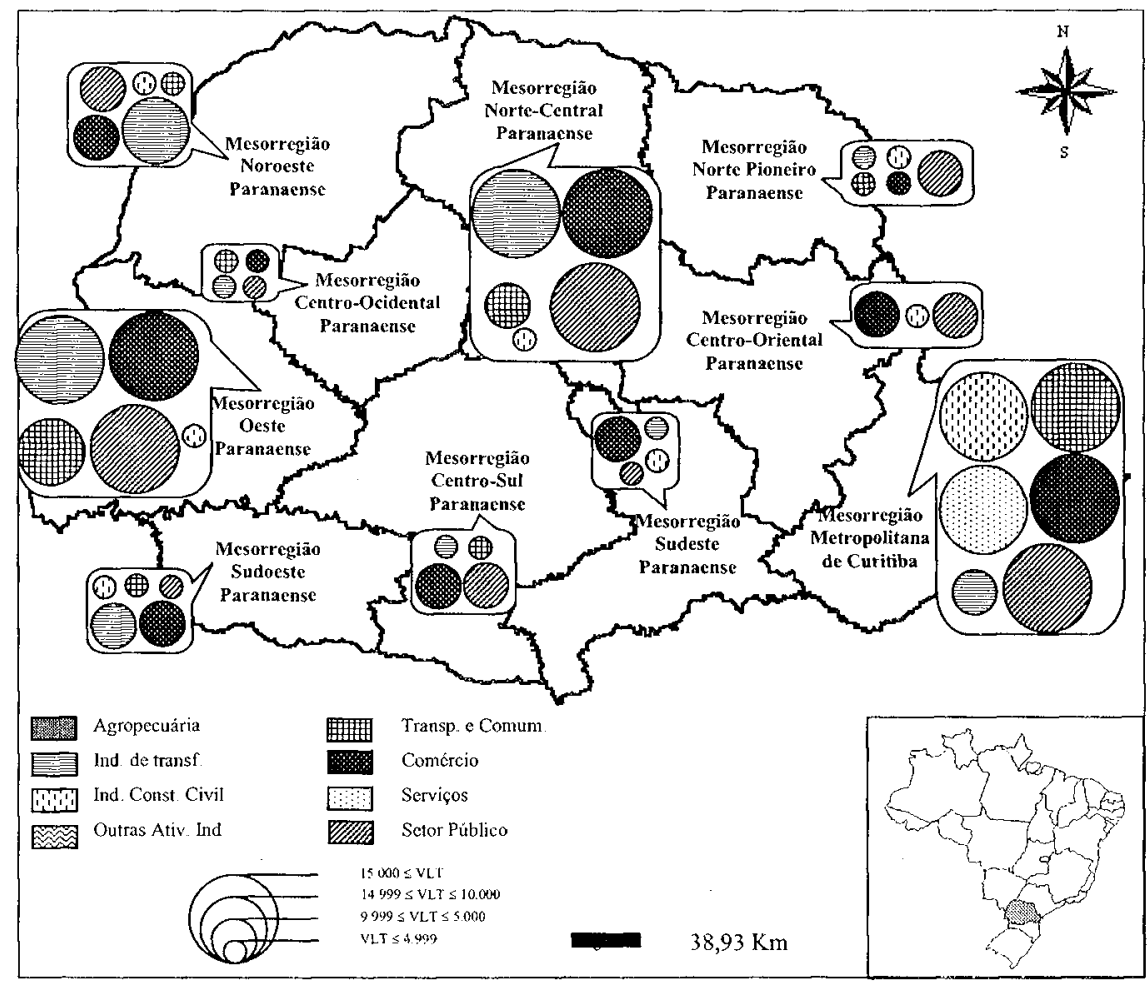

Figura 6.Variação liquida total (VLT') positiva das mesorregiões do estado do Paraná - 1991/2000

Fonte: Resultados da Pesquisa

\section{Conclusão}

O objetivo principal deste artigo foi fazer uma análise regional das mesorregiões do estado do Paraná nos anos de 1991 e 2000. Analisaram-se, através de um instrumental de análise regional, os desempenhos 
das mesorregiōes do Paraná no tocante aos seus setores, verificando os mais dinâmicos.

Com a aplicação dos métodos de análise regional, por meio dos coeficientes de localização e especialização, percebeu-se que os o setor da agropecuária é mais distribuído do estado. As atividades industriais se concentram em um corredor entre as mesorregiões Norte Central e Metropolitana de Curitiba. Das demais, somente a mesorregião Oeste se destaca no setor de outras atividades industriais. Com relação aos demais setores, notou-se uma concentração nas mesorregiões com maior densidade populacional, quais sejam: Oeste, Norte Central, Centro-Oriental e Metropolitana de Curitiba. Outrossim, notou-se uma interação entre as atividades produtivas ligadas aos setores secundário e terciário. Essa interação torna-se mais significativa e correlacionada com a densidade populacional, ou seja, com a urbanização. No caso dessas mesorregiões, o continuum produtivo é urbano-industrial, em contraste ao Centro-Sul, Sudoeste e Noroeste Paranaense que, dada as suas características geográficas e econômicas, ainda possuem muitos municípios com um continuum urbano-rural.

A análise shift and share, através da Variação Líquida Total, demostrou que os setores que mais se dinamizaram nas mesorregiões Paranaenses foram: comércio, setor público, indústria da transformação, indústria da construção civil e transporte e comunicação. Esses dados confirmam os demais coeficientes de análise regional ao mostrarem que a dinâmica econômica do Estado está pautada nos setores secundário e terciário.

Assim, outros estudos, utilizando variáveis distintas, devem ser elaborados, com vistas à comparação dos resultados da análise regional da mão-de-obra e à obtenção de um panorama mais amplo da estrutura locacional e da divisão inter-regional do trabalho e da produção do Estado do Paraná, subsidiando, assim, a formulação de apontamentos mais precisos em relação à dinâmica setorial das mesorregiões paranaenses.

\section{Referências}

COSTA, J. S. (Org.). Compêndio de Economia Regional. APDR. Coimbra: Gráfica de Coimbra Lda., Lisboa, APDR, 2002.

FERRERA DE LIMA, J. Méthode d'analyse régionale: Indicateurs de localisation, de structuration et de changement spatial. (Collection Notes et Rapports de Recherche). Saguenay: GRIR/UQAC, 2006.

FERRERA DE LIMA, J. ; PIACENTI, C. A.; ALVES, L. R. e PIFFER, M. A localização e as mudanças da distribuição setorial do PIB nos estados da regiāo Sul (1970-1998). In: Congresso brasileiro de economia e sociologia rural (SOBER), Cuiabá, Anais... Cuiabá: SOBER, 2004. I CD-ROM. 
HADDAD, J. H. (Org.). Economia regional: teoria e métodos de análise. Fortaleza: BNB/ ETIENE, 1989.

IBGE (Instituto Brasileiro de Geografia e Estatística). Banco de dados agregados. Disponivel em: <http:/www.sidra.ibge.gov.br/bda/>, Acesso em: 18 mar. 2005.

IPARDES (Instituto Paranaense de Desenvolvimento Econômico e Social). Perfil do Paraná. Curitiba: IPARDES, 1996.

IPEA (Instituto de Pesquisa Econômica Aplicada). Caracterizaçāo e tendências da rede urbana do Brasil: redes regionais: Sul. v. 6, IPEA, IBGE, UNICAMP/IE/NESUR, IPARDES. Brasilia: IPEA, 2000.

LODDER, C. A. Padrões locacionais e desenvolvimento regional. Revista Brasileira de Economia. V. 28, n. 1, Jan./Mar. 1974.

PAIVA, C. Á. N. Desenvolvimento regional, especialização e suas medidas. Indicadores Econômicos. Porto Alegre: FEE, v. 34, n. 1. jan./mar. 2006.

PIACENTI, C. A. et al. Análise regional dos municípios lindeiros ao lago da Usina Hidroelétrica de Itaipu. In: Encontro brasileiro de estudos regionais e urbanos, 2, 2002, São Paulo, Anais... São Paulo: ABER, 2002. 1 CD-ROM.

PIACENTI, C. A.; FERRERA DE LIMA, J. (Coord.). Análise do impacto dos reservatórios das hidroelétricas no desenvolvimento econômico microrregional. Toledo: UNIOESTE/ Campus de Toledo, março/2001. 245 p. (Relatório de Pesquisa. UNIOESTE - Campus de Toledo/Fundação Araucária - Projeto 612.) projeto concluído, 2002.

PIFFER, M. A Dinâmica do Oeste Paranaense: sua inserção na economia nacional. Curitiba, 1997. 200 f. Dissertação (Mestrado em Desenvolvimento Econômico) - Universidade Estadual do Paraná.

PUMAIN, D.; SAINT-JULIEN, T. Lanalyse spatiale: localizations dans l'espace. Paris: Armand Colin, 1997.

RIPPEL, R.; FERRERA DE LIMA, J. Encadeamentos produtivos e desenvolvimento regional no município de Toledo (PR): o caso da Sadia-Frigobrás e das indústrias comunitárias. In: Casimiro Filho, F.; Shikida, P. F. A. (Org.). Agronegócio e Desenvolvimento Regional. Cascavel: EDUNIOESTE, 1999, p. 31-56.

VOLLET, D.; DION, Y. Les apports potentiels des modèles de la base économique pour guider la décision politique. Reuue d'Économie Régionale et Urbaine (RERU), Bordeaux, n², p.179-196, 2001. 